\section{Calendar of Geographical Exploration}

\section{Nov. 2, I841, -Afghanistan and Its Borders}

Sir Alexander Burnes was assassinated while acting as political agent in Kabul. Burnes became an interpreter in Surat when only seventeen years of age and developed a keen interest in the history and geography of north-western India and the adjacent countries. In 1832, disguised as an Afghan, he started from Lahore, made his way across Afghanistan to Balkh, thence to Bukhara, Astrabad and Teheran, and across Persia to Bushire. In 1835 he returned to Afghanistan, taking with him John Wood. The latter explored the Kabul River, crossed the Hindu Kush mountains to the Oxus, and explored that river to one of its sources. $\mathrm{He}$ gathered much information about the nomad tribes of that region.

\section{Nov. 3, r924.-The R:o Negro and its Tributaries}

Dr. Hamilton Rice made his first air survey in the 1924-25 expedition to the Rio Branco and Uraricoera. Rice's valuable work on the northern portion of the Amazon basin began in 1907 , when he surveyed the Uaupes River to its junction with the Rio Negro. Further expeditions in 1912-13, 1917, 1919-20 and 1924-25 resulted in an accurate survey of the tributaries of the Rio Negro and of the river itself to Manaos.

\section{Nov. 4, 1909.--Exploration of Persia}

Sir Percy Sykes left Meshed on the second part of his sixth expedition into Persia. These six expeditions were of the utmost importance for the survey of Persia, and filled in many blank spaces on its map. Sykes's travels also threw new light on ancient geography ; in this sixth, 1906-10, journey he discovered the site of ancient Nishapur and also of Kishmar a spot connected by legend with Zoroaster.

\section{Societies and Academies}

\section{LONDON}

Physical Society, Oct. 21.-F. Twyman: New apparatus for rapid spectrophotometry of liquids in the ultra-violet. A single exposure, usually of less than 20 sec., results in a set of spectra which embodies all that is necessary for plotting an absorption curve.J D. Stephenson : An experimental study of electrical discharge in gases at normal temperatures and pressures. By an investigation based on corona discharge it is shown that there is a fixed constant, the true breakdown strength of the gas, for all types of gas discharge at normal pressures.-G. A. Tomlinson: A new type of pendulum clock. A new method of taking accurately defined seconds signals from a pendulum is described, in which a photoelectric cell is used in conjunction with a special arrangement of multiple slits. This has been developed into a complete free-pendulum system, self-maintained in vacuo by means of electrostatic impulses and having a closely governed arc.-S. E. Williams: A photographic method of deriving optical constants of the metals. A grating consisting of alternate strips of glass and metal of known dimensions gives diffraction spectra the relative intensities of which depend on the optical properties of the metal and glass. An expression has been found for the relative intensities of the central reflected image and the first principal diffracted image in terms of the reflection coefficients for the metal and glass and the phase change on reflection from the metal surface. By means of a photometric method which is described, the intensity ratio has been measured for two or more gratings of different proportions cut on the one mirror, enabling the deduction of the reflection coefficients and the change of phase. This is done both for light plane polarised in, and perpendicularly to, the plane of incidence, and the approximate Drude formulæ are used to calculate the optical constants. Simultaneous measurements can be made at several wave-lengths if the grating is illuminated with light from a source having a suitable line spectrum.

\section{PARIS}

Academy of Sciences, Sept. 12 (vol. 195, pp. 525532).-N. Saltykow: The complete integral of partial differential equations of the second order.-Pierre Marti: The possibility of determining the slope of the sea floor by means of acoustic sounding. When the sea floor is level the determination of the interval of time between the sound emission and the arrival of the echo gives the depth. If the sound is powerful, several echos are received and these are separated by equal intervals of time in the case of a horizontal sea floor, but if there is a slope, the intervals of time of the successive echos are not equal, and the exact comparison of these intervals can be used for determining the slope. A formula for this is given.V. Hourcq : The age of the glauconitic limestones of the Antsalova region (Province of Maintirano), Madagascar. It is possible that the limestone represents only the lowest part of the Kimmeridge strata and that the greater part should be regarded as Tithonic.

Sept. 19 (vol. 195, pp. 533-548).--J. Cantacuzène and S. Longhin: The experimental transmission of human leprosy to the white rat.-Louis de Broglie: An analogy between Dirac's electron and the electromagnetic wave.-J. Fromaget and F, Bonelli: Materials from Angkor and some points of the stratigraphy and the geological structure of northern and eastern Cambodia.-A. Rivière: Contribution to the study of the Jurassic in the central Elbourz.-L. Clariond, N. Gouskov and E. Roch: The ancient series of the country of Skoura (Central Moroccan Haut-Atlas).-Pierre Marty and Pierre Bout: The discovery of a layer of fossil plants in the Pliocene formation of Perrier, near Issoire (Puy-de-Dôme).Jean Caminopetros and B. Contos: The transmission of pustular fever to the guinea-pig.

Sept. 26 (vol. 195, pp. 549-564).-A. Caillon and R. de Fleury: Casting magnesium : use of a special sand. The addition of ammonium sulphate and powdered fluorspar to the sand used for moulds is recommended on the grounds of low cost for magnesium castings.-A. Rivière: The Cretaceous in the north of central Elbourz.-Jacques Fromaget: The Caledonian folds of the massif of Fan Si Pan (Tonkin). --Léon Grigorakis: The action of ether on the microplant parasites of animal tissue. Factors of virulence, vitality, degradation and mutation.-P. Cappe de Baillon: The thermal sensitiveness of the Phasmidæ.-A. Magnan and Ch. Perrilliat-Botonet: The relative weight of the motor muscles of the wings in insects-Jonesco-Mihaiesti, A. Tupa, B Wismer and G. Badenski: Acute pseudo-tabetic syndrome resulting from the experimental inocula. tion of the filtrate of inguinal lymphogranulome (Nicolas-Favre).

No. 3287, VoL. 130] 


\section{SYDNEY}

Linnean Society of New South Wales, June 29.C. Oke : Notes on Australian Coleoptera, with descriptions of new species (2). Two new genera and thirty-five new species belonging to various families are described. Probably the most interesting species described belongs to the family Rhysodidx, and is the first of the Australian species to be recorded as a myrmecophile.-A. B. Walkom : Fossil plants from Mount Piddington and Clarence Siding, N.S.W. Specimens from Mount Piddington include Cladophlebis australis, Thinnfeldia Feistmanteli, possible flowers of Williamsonia, and one which may be Phyllotheca robusta Feistmantel. From Clarence Siding a fertile specimen of a fern (?) with very long narrow pinnæ and sori of the Asterotheca type is described as a new genus. These plants occur near the western margin of the Hawkesbury Series basin, and it is difficult to correlate the horizon since, near the coast, the sandstone series has a thickness of about a thousand feet, but near the western margin the thickness is only about three hundred feet.H. L. Jensen : Contributions to our knowledge of the Actinomycetales. (3) Further observations on the genus Micromonospora. A description of sixty-seven strains of Micromonospora isolated from Australian soils. They are divided into four species-groups, one of which seems identical with 'Streptothrix' chalcroe Foulerton; the other three are described as new species. These organisms seem to occur most abundantly in neutral to alkaline soils from districts with a low rainfall.--J. R. Malloch : Notes on Australian Diptera (31). Certain species of the genus Prosena (Tachinidæ) are deseribed, three being new. A key is given for the identification of the species of Prosena.

Royal Society of New South Wales, Aug. 3.A. R. Penfold : The chemistry of Western Australian sandalwood oil. Conclusive and confirmatory evidence was submitted that the oil from the roots and butts yielded the best quality of oil for commercial purposes and differed considerably in chemical composition from that obtained from the stickwood. The paper was accompanied by two comprehensive tables setting forth the chemical and physical characters of each individual sample of oil together with the alcoholic bodies obtained from each by treatment with phthalic anhydride in benzene solution on a boiling water bath for two hours, as well as the yields of santalenic acid and santalol allophanate. An examination of the oil obtained from a consignment of butts said to be a fair average of the raw material used in the production of commercial Australian sandalwood oil showed it to contain more than fifty per cent of B-santalol.-Alma G. Culey: Ripplemarks in the Narrabeen series along the coast of New South Wales. Numerous exposures of oscillation ripple-marks have been observed over a large vertical range and wide area in the Narrabeen series (lower Triassic), of New South Wales. The dimensions of the ripple-marks and their association with plant remains, worm-burrows, and sun-cracks, point to quiet deposition of the Narrabeen beds in a very shallow, subsiding, fresh-water lake. Comparison of quantitative diagrams, indicating the directions of the ripple-marks and present-day winds, suggests that the planetary wind systems of lower Triassic time were the same as those prevailing now. Hence one may deduce that the poles were in the same position then as now.
WAShington, D.C.

National Academy of Sciences (Proc., 18, 481-523, July 15, 1932).-Marcus $M$. Rhoades: The genetic demonstration of double strand crossing-over in Zea mays.-Jack Schultz: The behaviour of vermilionsuppressor in mosaics. This factor in Drosophila depends on factors outside the mosaic tissues as does vermilion. Its effect seems to be exerted before the onset of pigment formation.-George C. Vaillant : Stratigraphical research in Central Mexico. Continuation of the American Museum of Natural History archæological work in the Valley of Mexico. It is concluded that the Teotihuacan culture was not derived from Valley groups of the Early periods, and a ceramic sequence of three periods is arranged. The Mazapan culture is dated as post-Teotihuacan and pre-Aztec.-David Davidson and Marston T. Bogert: Isovioluric acid (alloxan-6-oxime). Prepared by action of nitrous acid on isobarbituric acid. It is rearranged by acid, giving violuric acid and by reduction yields isouramil $(5,6$-dihydroxycytosine). -Edward W. Washburn and Harold C. Urey: Concentration of the $\mathrm{H}^{2}$ isotope of hydrogen by the fractional electrolysis of water. An experiment is in process at the Bureau of Standards. Meanwhile, spectrographic examination of the residues from the commercial hydrolysis of water showed there was increase in the abundance of $\mathrm{H}^{2}$ relative to $\mathrm{H}^{1}$.- Linus Pauling: The electronic structure of the normal nitrous oxide molecule. A recalculation of Plyler and Barker's data leads to a value of the moment of inertia which corresponds to a Lewis structure in which the nitrogen-nitrogen bond resonates between a double and triple bond and the nitrogen-oxygen bond between a single and double bond. The structure can be written $\mathrm{N} \equiv \mathrm{N}=\mathrm{O}$.- - Harvey Cushing : Further concerning a parasympathetic centre in the interbrain. (7) The effect of intraventricularly injected histamine. It has been objected to the observations recorded about a year ago that the effects after intraventricular injection of pituitrin and pilocarpine were due to impurities, probably histamine. Examination of the posterior lobe extract used showed it to be free from histamine. Further, intraventricular injection of histamine produces facial pallor rather than flushing.-(8) The comparative effects on gastric motility of intramuscular and intraventricular pituitrin, pilocarpine and histamine. Pituitrin and pilocarpine do not increase gastric acidity as does histamine. When given intraventricularly, both increase motility and lead to retrograde peristalsis and vomiting ; intramuscularly, they inhibit gastric peristalsis, but there is also a delayed acceleration of peristalsis with pilocarpine. Intramuscular pituitrin seems to stimulate the thoracolumbar sympathetic apparatus; intraventricular pituitrin appears to have a contrary effect, essentially parasympathetic in character.--G. A. Miller : Orders for which there exist exactly four or five groups.-J. L. Walsh: On interpolation to harmonic functions by harmonic polynomials.-A. E. Currier: Partial differentiation in the large.-Chester Stock: Eocene land mammals on the Pacific coast. The Sespe formation in Southern California comprises sandstones, shales and conglomerate. Vertebrate remains in the Simi Valley region in the maroon and green clays and sandstones of the middle divi. sion of the Sespe formation include titanotheres, rhinoceroses, artiodactyls (Protylopus), rodents (Para$m y s)$ and others indicative of the Eocene age.

No. 3287, Vou. 130] 